\title{
Fecundity, Survival and Susceptibility of Bedbugs (Cimex Hemipterus), Exposed to Selected Classes of Insecticides: A Short Report
}

MARY Aigbiremo OBOH ( $\sim$ aigbi4god@gmail.com )

Medical Research Council Unit The Gambia https://orcid.org/0000-0001-5720-8425

Taiye Shade Olusegun-Joseph

Yaba College of Technology

Adedayo Michael Awoniyi

Universidade Federal da Bahia

Maureen Ihinosen lleaboya

Yaba College of Technology

Bukola Tawakalitu Lawal

Yaba College of Technology

Ifeoluwa Kayode Fagbohun

University of Lagos

Short report

Keywords: Bedbugs, Insecticides resistance, Cimex hemipterus, ectoparasites, Nigeria

Posted Date: June 10th, 2021

DOI: https://doi.org/10.21203/rs.3.rs-592237/v1

License: (1) This work is licensed under a Creative Commons Attribution 4.0 International License.

Read Full License 


\section{Abstract}

Background: Tropical bed bug, Cimex hemipterus, is a nocturnal obligate blood-sucking ecto-parasite of humans that is highly prevalent in Nigeria. Bed bug control heavily relies on the application of several insecticides-based formulations. Insecticide resistance in bed bug populations has been widely reported. Here, we assessed the mortality and fecundity of bed bugs following exposure to different classes of insecticides.

Methods: Bed bugs were collected from students' halls of resident and exposed to DDT (4\%), permethrin (0.75), bendiocarb (0.1) and malathion (4\%) insecticide-impregnated papers. Mortality and number of eggs laid by each exposed groups were recorded at $24 \mathrm{hrs}, 48 \mathrm{hrs}$ and $72 \mathrm{hrs}$.

Results: The relative numbers of eggs produced by bedbugs in the DDT, bendiocarb and malathion assays were lower than what was observed in the control 24 hours after exposure. The highest reduction in egg production was observed in the malathion exposed-group compared to the other insecticides and the control group. The impact of the different assays on bugs mortality revealed DDT to produce a timedependent outcome with the highest death rate (36.7\%) recorded 24 hours' post-exposure. In contrast, malathion and bendiocarb impacted the most mortality (53.3\% and $46.6 \%)$ after 72 hours.

Conclusion: This study revealed an occurrence of suspected insecticide resistance to all classes of insecticide used in bed bug populations in Lagos State, Nigeria.

\section{Introduction}

Tropical bed bug (Cimex hemipterus) is a nocturnal ectoparasite of the family Cimicidae that is commonly distributed in the tropical and subtropical regions of the world [1]. Like in many other developing nations, high prevalence of bedbugs' infestation has been reported in homes and school dormitories across Nigeria [2] with high frequency in untidy and congested households [3]. Bedbug infestation rates of above $50 \%$ have been reported in most studied communities across the country $[4,5$, 6]. In such households, $C$. hemipterus usually hide in dry, dark places like in mattresses/pillows, carpets, furniture, abandoned appliances and walls/floors cracks [3] where they lay hundreds of eggs that hatch into the adult form.

The account of human-bedbug relationship is long dated before the Second World War. C. hemipterus constitutes a public health nuisance to mankind, their bites bring about considerable discomfort, social stigmatization and psychological distress (7). Although $C$. hemipterus are not directly associated with diseases transmission, they have been somewhat shown to aid in mechanical transmission of plague, hepatitis $B$ virus and tularemia $[2,8]$.

Following the invention of dichloro-diphenyl trichloroethane (DDT) among other insecticides, elimination of bedbug was considered successful especially in the developed world with sudden decline experienced in their population [1]. In Nigeria, chemical control using permethrin, DDT, bendiocarb and malathion 
remains a vital measure in the management of most insect pests [1]. Regrettably, resurgence of bedbugs' resistance to insecticides has been reported in the last two decades due to indiscriminate and repeated overuse of insecticides. Moreover, dissemination of mutant bedbugs as a result of unsupervised international travel has been on the increase [8]. Furthermore, cimicid insects have been documented to be highly resistant against organochlorines, organophosphates (OPs), carbamates and pyrethroids worldwide $[9,10]$, thereby leaving pyrethroids as the most widely used class of insecticide for bedbug control [8].

Diverse resistance mechanisms such as penetration resistance through thickening of the cuticle, metabolic resistance by increased activities of detoxification enzymes and knockdown resistance by $k d r$ mutations have been demonstrated to be responsible for the conferment of resistance statue displayed by bedbug $[1,11]$.

Although, reported resistance activities of bedbug to chemical treatment is evident in major high income countries, equivalent of such is scanty or non-available in the tropics especially Nigeria. Understanding their rate of survival, fecundity and resistance to chemical treatment is paramount if $C$. hemipterus are to be effectively managed in this part of the world. It is based on this fact that, we evaluated the susceptibility status of field collected bedbugs to four classes of selected insecticides (permethrin, dichloro-diphenyl trichloroethane (DDT), bendiocarb and malathion) using WHO standard test kits. This finding will provide useful information for those attempting to manage bedbug infestations, such as pest management professionals and homeowners in developing an informed control strategies aimed at current and future infestations.

Bedbug samples were collected from seven randomly selected buildings (four classrooms: Civil Engineering, New building, Mechanical Engineering and Multipurpose building) and (three hostels: Akata, New hall and PGD hall) in Yaba College of Technology (Yabatech), Yaba, Lagos State, Nigeria.

Yaba College of Technology (Yabatech) is a higher institution based in Yaba, located on longitude 030 22E and latitude $06030 \mathrm{~N}$, surrounded by Fadeyi, Shomolu, Herbert Macauley way and Fola Agoro. The student population is about 16,000 with majority from typical Nigerian average homes, that is, children of middle-low income earners. The school has six hostel accommodations for the students which are always almost packed beyond capacity, a condition that favours bedbug infestation

A total of two hundred and seventy (270) bedbugs were harvested. Collections were done between 8pm $10 \mathrm{pm}$ daily from May to August 2019 following the methods previously described by Punchihewa et al. (2019). The collected bedbugs were transferred to the Yabatech Environmental Biology Laboratory in well labelled containers and they were maintained in aerated clean plastic containers at a temperature of $25 \pm$ $2^{\circ} \mathrm{C}$ and relative humidity of $75 \pm 10 \%$. The samples were maintained for 24 hours before exposure to insecticides.

Insecticide susceptibility bioassay were conducted using insecticide impregnated filter paper with $0.75 \%$ permethrin, $4 \%$ DDT, $0.1 \%$ bendiocarb and $5 \%$ malathion. The bioassays were carried out using WHO 
insecticides test kit and were covered with cloth having very tiny mesh at both ends enough to prevent the bedbugs from escaping during exposure and supply the optimum air. Each bioassay contains fifteen bedbugs exposed to the insecticide-impregnated papers, the assay was carried in four replicates and accompanied by a control. During the exposure, the test tubes were constantly agitated to ensure the bedbug were on the insecticides impregnated papers. The insecticides exposure was carried out for 90 minutes, and the bedbugs were transferred to another aerated container with non-treated paper. Mortality and number of eggs produced were recorded at 90 minutes, 24,48 and 72 hours.

Percentage mortality and egg production were computed per assay.

Egg production rate $=$ number of eggs produced/ total number of bedbugs present at the beginning of every 24 hrs X 100

Percentage mortality = number of dead bedbugs/ total number of bedbugs present at the beginning of every $24 \mathrm{hrs}$ X 100

The mortality of bedbugs in relation to exposure to insecticides and time was determined using univariate analysis of variance and Duncan multiple range test used for post hoc at $95 \%$ confidence interval and $0.05 \mathrm{p}$-value.

All analyses were done in IBM SPSS version 23.

\section{Results And Discussion}

Bedbugs' infestation has been reported to recently have a worldwide resurgence. They have also been associated with stigmatization, sleeplessness, psychological and social distress [2, 12]. In Nigeria, there are not enough epidemiological studies on the distribution of bedbugs and their susceptibility status to various public health insecticides. Insecticidal resistance is a serious public health challenge globally against pest and vector control efforts and as such, there is need for constant monitoring and evaluation of the potency of major insecticides.

The relative numbers of eggs produced by bedbugs in the DDT, bendiocarb and malathion assays were lower than what was observed in the control 24 hours after exposure, while the effect of permethrin on fecundity was not much different from the control (Fig. 1). Evaluation of the fecundity after 48 hours showed malathion to have the most potency against egg production, followed by permethrin, while DDT and bendiocarb displayed same potency. In same manner, assessment of bedbugs' fecundity after 72 hours revealed malathion to have the most potent outcome on egg reduction. Taken together, malathion showed a time-dependent potency after 72 hours (Figure. 1). The observation of substantial reduction in egg production 48 and 72 hours after exposure to malathion is similar to a previous study that reported that high reduction in egg production after bedbugs were treated with moxidectin [12]. Thus malathion is shown to be efficient and have potency against Cimex hemipterus. 
Evaluating the impact of the different assays on bugs mortality showed that DDT produced a timedependent outcome with the highest death rate (36.7\%) recorded 24 hours post exposure. The implication of this is that the effect of insecticide reduces by the hour and some point in time (48-72 hours as seen in this study), the potency will no longer be enough to reduce the population of Cimex. In contrast, malathion and bendiocarb impacted the most mortality $(53.3 \%$ and $46.6 \%)$ after 72 hours. The percentage of death after permethrin exposure showed no particular time pattern as more deaths were recorded 24 and 72 hours (26.7\% and $18.9 \%$ ) post-exposure and less after 48 hours (15.9\%) (Table 1 ). Together, the mortality rates observed from the insecticides exposed bedbugs were statistically different from the non-exposed control group. This is in accordance to a previous study that also reported the efficacy of malathion and pyrethroids in killing bedbugs [13].

Table 1

Mortality of bedbugs exposed to different insecticides

\begin{tabular}{|llllll|}
\hline Insecticides & $\begin{array}{l}\text { No } \\
\text { exposed }\end{array}$ & $\begin{array}{l}\text { 24 hours } \\
\text { mortality (\%) }\end{array}$ & $\begin{array}{l}\text { 48 hours } \\
\text { mortality (\%) }\end{array}$ & $\begin{array}{l}\text { 72 hours } \\
\text { mortality (\%) }\end{array}$ & $\begin{array}{l}\text { Mean } \\
\text { mortality }\end{array}$ \\
\hline Control & 30 & 0 & 6.7 & 10.5 & $1.0 \pm 1.0^{\mathrm{a}}$ \\
\hline DDT & 60 & 36.7 & 28.9 & 14.8 & $2.50 \pm$ \\
\hline Permethrin & 60 & 26.7 & 15.9 & 18.9 & $2.02^{\mathrm{b}}$ \\
\hline Bendiocarb & 60 & 31.6 & & & $2.33 \pm$ \\
& & & 41.7 & 46.6 & $2.27^{\mathrm{b}}$ \\
\hline Malathion & 60 & 26.7 & & & $2.67 \pm$ \\
& & & 45 & 53.33 & $1.30^{\mathrm{ab}}$ \\
\hline
\end{tabular}

NB

Superscript $a$ and $b$ indicate similarities in mean values at $P<0.05$

This study shows different levels of reduced susceptibility of $C$. hemipterus to the four selected insecticides at different time intervals. There is therefore a need for continuous and comprehensive evaluation of Cimex response to all classes of approved insecticides. DDT which reduced not only bedbug survival rate, but also their egg production rate could be safely recommended for use and would be more useful in controlling the domestic nuisance caused by $C$. hemipterus.

Although, this study is limited in its study area and genetic evaluation of target genes in the bedbugs that might be associated with the reduced potency. However, the results obtained here forms the basis for future work that will involve varied study areas and genetic population analysis.

\section{Declarations}


Ethical Approval

Approval for collection of bedbug from the student halls of residence was sought from Yaba College of

Technology administrators.

Consent for publication

Not applicable

Availability of data and materials

All data generated or analysed during this study are included in this manuscript

Competing interest

The authors have declared that no conflict of interest exists.

Funding

This study did not receive any form of funding

Authors' contribution

Conceptualisation: IKF. Data curation: MII, BTL, IKF. Formal analysis: IKF. Writing original draft: MAO, TSO, IKF. Writing - review and editing: MAO, TSO , AMA, IKF.

Acknowledgements

The authors wish to thank the staff of Environmental Biology Laboratory, Department of Biological Science, Yaba College of Technology for their support.

\section{References}

1. Dang K, Doggett SL, Veera Singham G, Lee CY. Insecticide resistance and resistance mechanisms in bed bugs, Cimex spp. (Hemiptera: Cimicidae) Parasites and Vectors. 2017; 10:1-31.

2. Emmanuel Ol, Cyprian A, Agbo OE. A survey of bedbug (Cimex lectularius) infestation in some homes and hostels in Gboko, Benue State. Nigeria Psyche (London). 2014. https://doi.org/10.1155/2014/762704.

3. Bonnefoy X, Kampen H, Sweeney K. Public Health Significance of Urban Pests. World Health Organization. 2008. https://doi.org/10.1007/978-3-319-13884-8_31.

4. Oduola AO, Omotayo Al, Adelaja OJ, Obembe A. Bedbug (Cimex lectularius) infestation and its control practices in two selected settlements in Ilorin, Kwara State, Nigeria. Animal Res Int. 2017;14(3):2818-25. 
5. Okwa 00, Omoniyi AO. The prevalence of headlice (Pediculus humanus capitis) and bedbug (Cimexhemipterus) in selected human settlement areas in south-west Lagos state, Nigeria. $\mathrm{J}$ Parasitol Vector Biol. 2008;2(2):8-13.

6. Omudu EA, Kuse CN. Bedbug infestation and its control practices in Gbajimba: a rural settlement in Benue state, Nigeria. J Vector Borne Dis. 2010;47(4):222.

7. Karunaratne SHPP, Damayanthi BT, Fareena MHJ, Imbuldeniya V, Hemingway J. Insecticide resistance in the tropical bedbug Cimex hemipterus. Pestic Biochem Physiol. 2007;88(1):102-7. https://doi.org/10.1016/j.pestbp.2006.09.006.

8. Punchihewa R, de Silva WPP, Weeraratne TC, Karunaratne SP. Insecticide resistance mechanisms with novel 'kdr'type gene mutations in the tropical bed bug Cimex hemipterus. Parasites Vectors. 2019;12(1):310.

9. Balvín O, Booth W. Distribution and frequency of pyrethroid resistance-associated mutations in host lineages of the bed bug (Hemiptera: Cimicidae) across Europe. J Med Entomol. 2018;55(4):923-928.

10. Cambronero-Heinrichs JC, Sánchez-Portilla LS, Calderón-Arguedas Ó, Troyo A. Cimex lectularius Linnaeus, 1758 (Hemiptera: Cimicidae) in Costa Rica: First Case Report Confirmed by Molecular Methods in Central America. J Med Entomol. 2020;XX(X):1-5.

11. Adelman ZN, Kilcullen KA, Koganemaru R, Anderson MA, Anderson TD, Miller DM. Deep sequencing of pyrethroid-resistant bed bugs reveals multiple mechanisms of resistance within a single population. PLoS One 2011;6(10).

12. Zha C, Wang C, Sheele JM. Effect of moxidectin on bed bug feeding, development, fecundity, and survivorship. Insects. 2017;8:1-10. https://doi.org/10.3390/insects8040106.

13. Berenji F, Moshaverinia A, Jadidoleslami A, Shamsian A, Doggett SL. Moghaddas E. Evaluation of the Common Bed Bug. Cimex lectularius (Insecta: Hemiptera: Cimicidae) Susceptibility to $\lambda$-Cyhalothrin, Malathion, and Diazinon in Northeastern Iran. J Med Entomol. 2019;56:903-6. https://doi.org/10.1093/jme/tjz011.

\section{Figures}




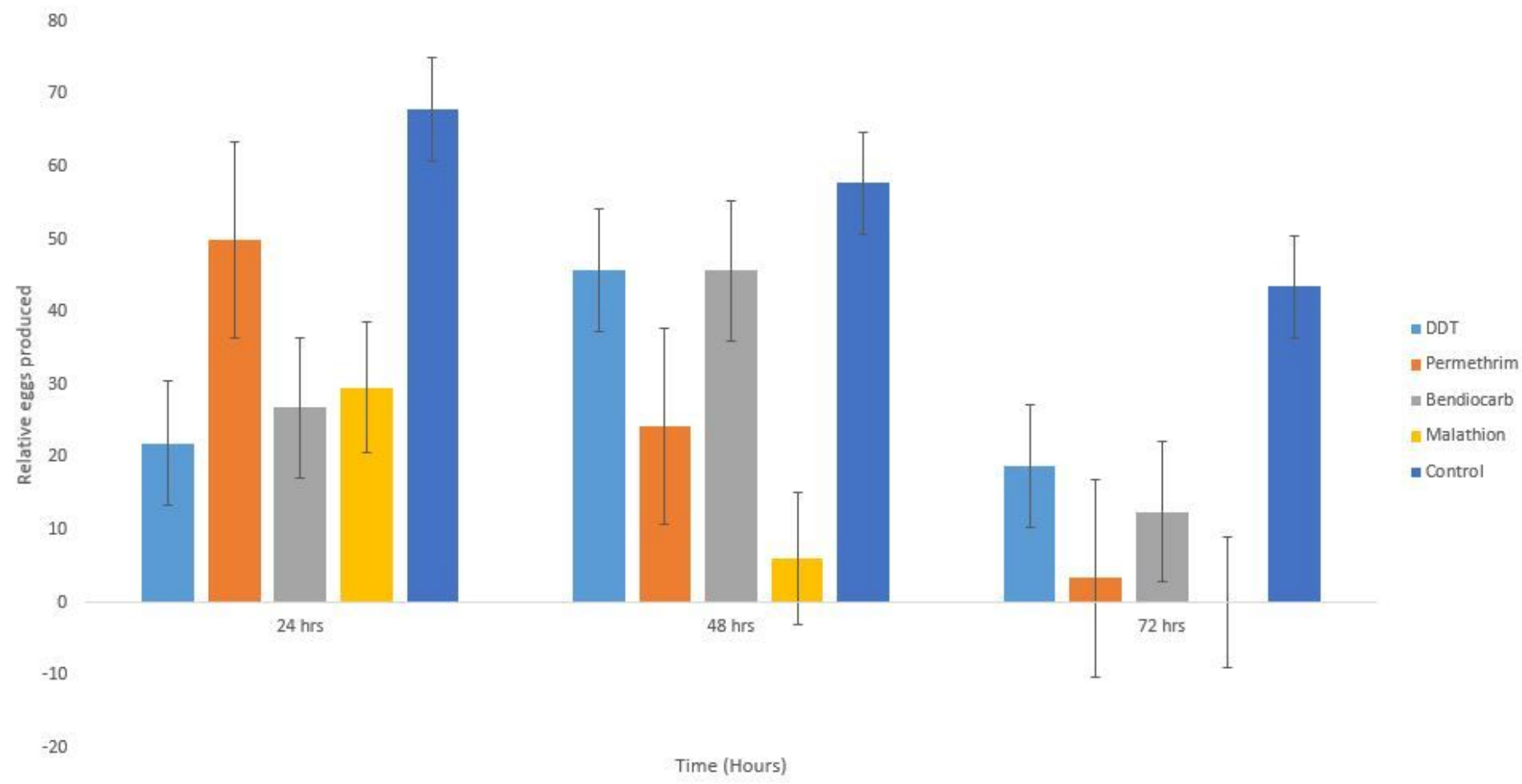

Figure 1

Daily eggs production rate in bedbugs after exposure to insecticides

\section{Supplementary Files}

This is a list of supplementary files associated with this preprint. Click to download.

- Graphicalabstract.pptx 